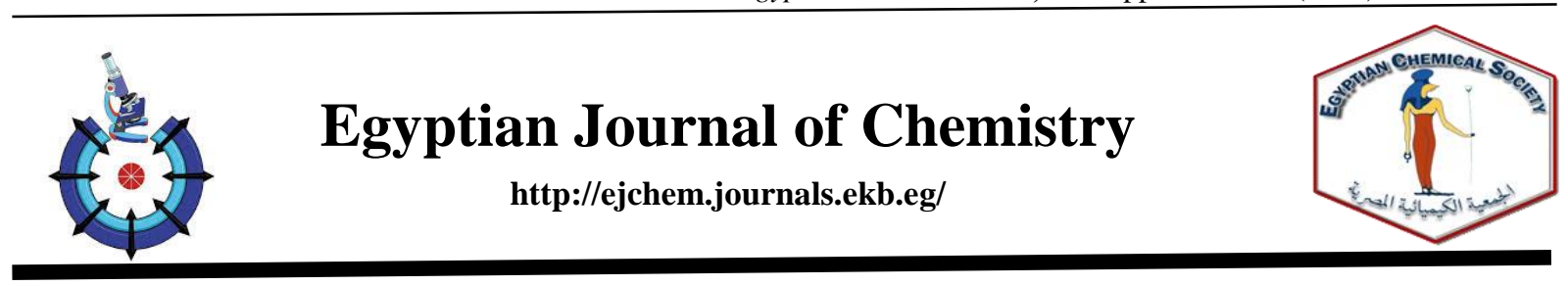

\title{
Corrosion Inhibition of Copper in Acidic Solution by using a Natural Product as Henna Extract (Lawsonia inermis L) \\ A. Diab, ${ }^{a, b, *}$ S. M. Abd El-Haleem ${ }^{a}$ \\ ${ }^{a}$ Chemistry Department, Faculty of Science, Zagazig University, Zagazig, (EGYPT). \\ ${ }^{b}$ Chemistry Department, Faculty of Science, Jazan University, Jazan, (K.S.A).

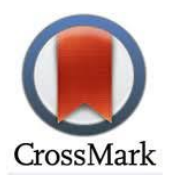

\begin{abstract}
The dissolution of the copper in naturally aerated $\mathrm{HCl}$ solution is studied at different acid concentrations using open circuit potential measurements, weight loss measurements, and galvanostatic polarization techniques. The rate of corrosion of the metal depends on acid concentration. Henna leaves (Lawsonia inermis L) extract is used as a naturally corrosion inhibitor for the corrosion of $\mathrm{Cu}$ in $0.5 \mathrm{M} \mathrm{HCl}$ solution. The inhibition efficiency of the henna extract depends on its concentration. Lower concentrations of the extract (2-4\%) cause slight effect on metal dissolution. In presence of $6 \%$ of the extract, a competitive process occurs between metal dissolution and metal inhibition. However, higher concentrations of the extract $10 \%$ caused marked inhibition of the metal (58.7\%). Inhibition of $\mathrm{Cu}$ dissolution in $\mathrm{HCl}$ solutions is assumed to be due to the formation of a $\mathrm{Cu}^{2+}$ - Lawsone complex on the anodic sites and the possible precipitation of $\mathrm{Cu}(\mathrm{OH})_{2}$ on the cathodic sites of the metal surface.
\end{abstract}

Keywords: Copper $(\mathrm{Cu})$, Hydrochloric acid $(\mathrm{HCl})$, Open circuit, Weight loss, Galvanostatic Polarization, Lawsonia inermis L.

\section{Introduction}

Owing to their high thermal conductivity, good corrosion resistance, and mechanical workability, copper and its alloys are widely used in many technical and industrial fields such as heating and cooling devices. In the nuclear industry, copper alloys are also used in condensers where the steam after turning the turbine is required to be cooled. In acid solutions of $\mathrm{pH} \mathrm{3,} \mathrm{the} \mathrm{copper} \mathrm{surface} \mathrm{was}$ covered with porous corrosion products of cuprous oxide $\left(\mathrm{Cu}_{2} \mathrm{O}\right)$. In solutions of $\mathrm{pH} 4$ to $\mathrm{pH}$, the formation of cubic $\mathrm{Cu}_{2} \mathrm{O}$ on the copper surface provided a diffusion barrier to copper dissolution. The anodic oxidation of copper is controlled by the mixed diffusion of copper ions in oxide films and in solution [1].

Hydrochloric acid is the most widely used acid pickling solution because it can dissolve the oxide on the surface of the metal rapidly. The condition of the metal surface is relatively better after pickled in $\mathrm{HCl}$. However, the pickled equipment suffers corrosion by $\mathrm{HCl}$ considerably. It has been reported that the anodic corrosion of $\mathrm{Cu}$ in $\mathrm{Cl}$ - media is affected by the concentration of chloride ions [2-10]. At little concentrations of chloride ions, the dissolution of $\mathrm{Cu}$ is due to the formation of $\mathrm{CuCl}$ that converts to soluble $\mathrm{CuCl}_{2}^{-}$through reacting with excess chloride. While, at high concentrations, cuprous complexes such as $\mathrm{CuCl}_{3}{ }^{2-}$ and $\mathrm{CuCl}_{4}{ }^{3-}$ are formed in addition to the ones with fewer chlorides such as $\mathrm{CuCl}$ and $\mathrm{CuCl}_{2}{ }^{-}$. Therefore, the utilization of some compounds that used as inhibitors is one of the best important methods to decrease the dissolution of $\mathrm{Cu}$ is such a destructive medium [11]. Consequently, it is of importance to reduce the destructive effect of hydrochloric acid on the devices during the cleaning process [12].

Several inorganic and organic inhibitors were used to control the corrosion of copper in acid media. Examples of inorganic inhibitors, El-Sherbini et al [13] studied the role of potassium chromate and sodium molybdate on the corrosion of copper in $\mathrm{HCl}$ solution using the potentiodynamic technique, and Electro impedance spectroscopy (EIS). On the other hand, several organic compounds were investigated as corrosion inhibitors for copper in acidic media. For

*Corresponding author e-mail: ahmeddeiab.72@gmail.com.; (Ahmed Diab Khater).

EJCHEM use only: Received date: 17 May 2021; revised date: 02 August 2021; accepted date: 11 August 2021.

DOI: 10.21608/EJCHEM.2021.66539.3747

(C2022 National Information and Documentation Center (NIDOC) 
example, triazole and some of its derivatives were used for the inhibition of copper in $\mathrm{HCl}$ solutions [14-17], while Cetyltrimethylammonium Bromide was used by Houyi Ma et al. [18] to inhibit $\mathrm{Cu}$ in $\mathrm{H}_{2} \mathrm{SO}_{4}$ solution.

Recently, green naturally product formulations are extensively used as promising alternatives to the always usual toxic organic and inorganic corrosion inhibitors. These formulations are environmentally safe substances, ecologically acceptable and economically sheep. Plant extracts are considered as good sources of constituents which prevent metal corrosion. The inhibition action of many plant extracts could be attributed to the presence of heterocyclic constituents like flavonoid and alkaloid [19]. The presence of cellulose, polycyclic compounds and tannin could increase the passive film formation over the metal surface causing better protection against corrosion [20]. Hart Kalada et al. [21] studied the inhibitive action of Xanthosoma spp Leaf extracts (XLE), as an example of green natural products, on the corrosion of copper in seawater using the weight loss technique.

Among the green natural products used, henna leaves extract was used as corrosion inhibitor for several metals. Henna has four primary constituents which are lawsone, gallic corrosive (3,4,5Trihydroxybenzoic acid), $\alpha$-D-Glucose and tannic (1,2,3,4,6-Pentakis-O-\{3,4-dihydroxy-5-[(3,4,5-

trihydroxybenzoyl)oxy]benzoyl $\}-\beta-\mathrm{D}$ -

glucopyranose). These constituents have incredible restraint capacity which could join with metal cations and adsorb on the metal surface as an arrangement of insoluble complexes to shield the metal from the dissolution process [22].

The henna extract has inhibitory activity on carbon steel in corroded media [23, 24]. It has been utilized as corrosion inhibitor for iron in $\mathrm{HCl}$ solution [25] and tin in acidic and alkaline solutions [26, 27]. Fouda et al. [28], on the other hand, used the extract of henna (Lawsonia Inermis) leaves as a green corrosion inhibitor for carbon steel (C-steel) in $1 \mathrm{M}$ $\mathrm{HCl}$ solution. On the other hand, Hajar et al. [29] investigated the effect of Henna (Lawsonia Inermis) as a corrosion protector for mild steel in seawater. However, others used Henna extract in acrylic resin coating [30] or in Hybrid coating [31] for steel in $\mathrm{HCl}$ solutions. El-Shamy et al. [32, 33] used the plant extracts as metallic corrosion inhibitors of steel alloy in $3.5 \% \mathrm{NaCl}$ solution.

The aim of the present work is to shed more light on the corrosion behavior of copper in $\mathrm{HCl}$ solutions free of and in presence of increasing proportions of henna extract. The effects of increasing concentrations of $\mathrm{HCl}$ solutions, immersion time and henna extract additives on the rate of corrosion and inhibition processes are examined.

\section{Experimental}

2.1. Metal. Experiments were carried out using copper metal having the following composition (weight \%): $0.027 \% \mathrm{Ni}, 0.067 \% \mathrm{Zn}, 0.006 \% \mathrm{Se}$, and the remainder $\mathrm{Cu}(99.90 \%)$.

2.2. Henna Extract. An aqueous extract solution used in the present investigation was prepared by grinding $50 \mathrm{~g}$ of dried Henna. (Lawsonia inermis L) leaves, filtered and diluted using triply-distilled water to $500 \mathrm{~mL}$.

2.3. Solutions. Solutions of $\mathrm{HCl}$ with variable concentrations were prepared by diluting the proper volume of concentrated $\mathrm{HCl}(36 \%)$ by triply-distilled water. The concentration range of the Henna extract (inhibitors) used was from $2 \%$ to $10 \%$. Experiments were approved at a constant temperature of $25 \pm$ $0.1^{\circ} \mathrm{C}$. Ultra-thermostat type polyscience (USA) was used to control the temperature degree.

2.4. Weight loss measurements. Copper pieces of 2.5 $\times 2.0 \times 0.2 \mathrm{~cm}$ were roughened with emery paper, Behr-Manning Company, Troy, New York (grades 320-500-800) and washed with demineralized water and acetone. After precise weigh up, the samples were submerged in a $250 \mathrm{~mL}$ of the tested solution devoid of- and containing increasing concentrations of henna extract. After then, the samples were taken out, washed, dried, and weighted precisely. The average weight loss of three similar copper sheets was considered. The percentage of inhibition efficiency (IE \%) and the degree of surface coverage, $\theta$, of henna extract was calculated as follows,

$\mathrm{IE} \%=\theta \times 100=\left[\mathrm{W}^{\mathrm{o}}-\left(\mathrm{W} / \mathrm{W}^{\mathrm{o}}\right)\right] \times 100$

where $\mathrm{W}^{\mathbf{0}}$ and $\mathrm{W}$ are the middling weight loss in solutions free of- and containing the added henna extract, respectively.

2.5. Open circuit potential measurements. The potential of the working electrode was measured for a period of 2 hours to the closest $\mathrm{mV}$ on a Wenking potentiometer type PPT 70 with respect to the 
reference calomel electrode (SCE). For every studied concentration, duplicate estimations of the potential of working electrode were finished and the mean estimation of the two readings was taken in attention. The divergence in potential measurements of the working electrode estimations was assessed to be under $\pm 5 \mathrm{mV}$. Steady-state potential was considered when the values of electrode potential remain constant or not change by more than $1 \mathrm{mV}$ in 10 minutes.

2.6. Galvanostatic polarization measurements. In this part of the work, tests were applied in an exceeding cell with three openings, one for the working electrode, the second for a Pt counter electrode and the third fo a standard calomel reference electrode (SCE). The copper working electrode used for open circuit and polarization measurements was prepared from a copper rode having the same chemical composition, with a diameter of $0.350 \mathrm{~cm}$. The electrode became installed to a salt glass pipe with epoxy glue so as the exposed surface area became $0.785 \mathrm{~cm} 2$. Electric contact was accomplished via a dense copper wire bound to the end of the copper bar not exposed to the solution. Before being employed, the metal was injured into uniform surface by a grinding apparatus (model Jean Wirtz TG 200, Germany) using sequent 0-, 00- and 000-grades emery papers, flushed with distilled water before immersing in the test solution. The SternGeary strategy was utilized for the assurance of corrosion current by extrapolation of the anodic and cathodic Tafel lines to the relating corrosion potential $\left(\mathrm{E}_{\text {corr }}\right)$ for the respective test solution. The corrosion current $\left(i_{\text {corr }}\right)$ was utilized for calculation of the percentage IE and $\theta$ as illustrated:

IE $\%=\left[1-\left(i_{\text {corr }}(\right.\right.$ inh $) / i_{\text {corr }}($ free $\left.\left.)\right)\right] \times 100=\theta \times 100$ (2) where, $i_{\text {corr }}\left(\right.$ free) and $i_{\text {corr }}(i n h)$ are the corrosion current densities in the devoid of- and containing henna extract, respectively.

\section{Results and discussion}

\subsection{Weight-lossmeasurements}

For studying the dissolution of copper in hydrochloric acid media and its inhibition by henna extract, the loss in weight testing was conceded. The variation in loss of copper sampled in $250 \mathrm{ml}$ of different concentrations of $\mathrm{HCl}$ versus time is shown in Fig.1. However, in Fig. 2, the effect of increasing concentrations of henna extract on the loss in weight of $\mathrm{Cu}$ in $0.5 \mathrm{M} \mathrm{HCl}$ is realized. Figure 1 indicates that, in one and the same concentration of $\mathrm{HCl}$, the loss in weight of $\mathrm{Cu}$ increases directly and linearly with immersion time and becomes more significant with increasing the acid concentration. This could be attributed to the disintegration of copper metal. At this state, the $\mathrm{Cu}$ cations are assumed to go to solution equation (3) reacting with $\mathrm{Cl}^{-}$ions to form $\mathrm{CuCl}$ equation on the metal surface eq. (4). The resulted cuprous chloride gives no sufficient protection to the electrode surface and reacts with the excess $\mathrm{Cl}^{-}$ions to give soluble $\mathrm{CuCl}_{2}{ }^{-}$complex as can be detected from equation (5) $[2-6,11,31]$, $\mathrm{Cu}=\mathrm{Cu}^{+}+\mathrm{e}^{-}$(fast)

$\mathrm{Cu}^{+}+\mathrm{Cl}^{-}=\mathrm{CuCl}$

$\mathrm{CuCl}+\mathrm{Cl}^{-}=\mathrm{CuCl}_{2}^{-}$

The formed $\mathrm{CuCl}_{2}{ }^{-}$complex oxidizes further to cupric ions according to the reaction $\mathrm{CuCl}_{2}^{-}$(solution) $=\mathrm{Cu}^{+2}+2 \mathrm{Cl}^{-}+\mathrm{e}^{-}$

The influence of adding of increasing concentrations of henna extract on the loss in weight of copper in $0.5 \mathrm{M} \mathrm{HCl}$ solution was further examined. Figure 2 represents the change of the loss in weight of the copper specimens with immersion time in naturally aerated $0.5 \mathrm{M} \mathrm{HCl}$ solutions free of- and containing increasing percentages of henna extract, at $25^{\circ} \mathrm{C}$. Inspection of the curves of Figure 2 reveals that, in presence of henna extract, loss in weight of the copper specimens is decreased and becomes higher the higher the concentration of henna extract. This action could be credited to a competitive step, including passive film healing by the henna extract and passive film damage by the aggressive $\mathrm{Cl}^{-}$ions.

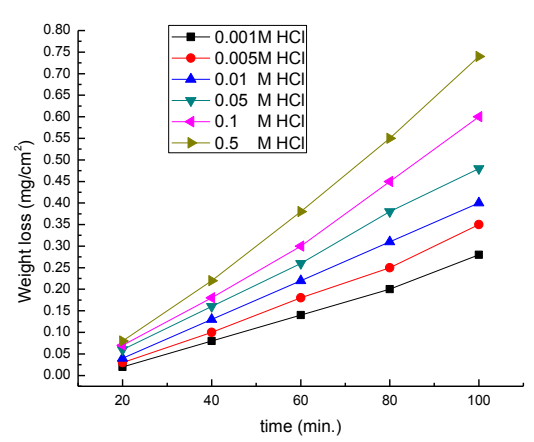

Figure 1. Variation of loss in weight of copper with immersion time at variable concentrations of $\mathrm{HCl}$ solution at $25^{\circ} \mathrm{C}$. 


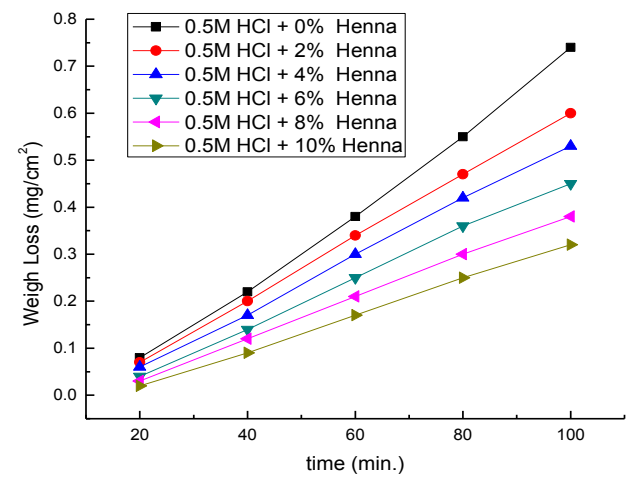

Figure 2. Variation of weight loss of copper with immersion time in $0.5 \mathrm{M} \mathrm{HCl}$ containing increasing concentrations of Henna extract at $25^{\circ} \mathrm{C}$.

Further inspection of figure (2) and Table (1) show that the inhibition efficiency of henna extract increases continuously with increasing its concentration to reach a value of $58.7 \%$ in presence of $10 \%$ of the extract after $100 \mathrm{~min}$. immersion.

Table 1. Variation of IE of copper immersed in $0.5 \mathrm{M}$ $\mathrm{HCl}$ in presence of different concentrations of henna extract, at $25^{\circ} \mathrm{C}$.

\begin{tabular}{|c|c|c|c|c|c|}
\hline & \multicolumn{5}{|c|}{$\% \mathrm{IE}$} \\
\cline { 2 - 6 } time, & $0.5 \mathrm{M}$ & $0.5 \mathrm{M}$ & $0.5 \mathrm{M}$ & $0.5 \mathrm{M}$ & $0.5 \mathrm{M}$ \\
min. & $\mathrm{HCl}+$ & $\mathrm{HCl}+$ & $\mathrm{HCl}+$ & $\mathrm{HCl}+$ & $\mathrm{HCl}+$ \\
& $2 \%$ & $4 \%$ & $6 \%$ & $8 \%$ & $10 \%$ \\
& $\mathrm{Henna}$ & $\mathrm{Henna}$ & $\mathrm{Henna}$ & $\mathrm{Henna}$ & $\mathrm{Henna}$ \\
\hline 20 & 6.2 & 13.7 & 31.2 & 43.7 & 50.0 \\
\hline 40 & 9.1 & 20.4 & 33.1 & 44.4 & 54.4 \\
\hline 60 & 10.5 & 21.0 & 34.2 & 45.7 & 55.2 \\
\hline 80 & 14.5 & 23.6 & 36.4 & 46.5 & 56.5 \\
\hline 100 & 18.9 & 28.3 & 39.2 & 48.6 & 58.7 \\
\hline
\end{tabular}

\subsection{Potential time measurements}

Figure 3 represents the corrosion behavior of $\mathrm{Cu}$ in different concentrations of hydrochloric acid varying between $1 \times 10^{-3} \mathrm{M}$ and $0.5 \mathrm{M}$ as revealed from open circuit potential measurements. Scale your artwork in your graphics program before incorporating it in your text. If the artwork turns out to be too large or too small, resize it again in your graphics program and re-import it, or use the sizing handles at the corners. Review of the bends of this figure uncovers that the steady-state potentials, $E_{s t}$, of the copper electrode is invariably approached from slightly positive values and becomes more active the higher the concentration of the acid reaching constancy after $\sim 60-90 \mathrm{~min}$. The steady-state potential, $E_{s t}$, is related to the logarithm of the molar concentration of $\mathrm{HCl}$, Figure 4, with a straight-line relation [34-37]:

$E_{s t}=\mathrm{A}+\mathrm{B} \log C_{H C l}$

wherever $\mathrm{A}$ and $\mathrm{B}$ are constants that hinge on the concentration of a tested solution and the electrode under study. The assessment of $\mathrm{A}=-186.17 \mathrm{mV}$ (SCE) signifies the steady state potential of the copper electrode, $E_{s t}$, in $1 \mathrm{M} \mathrm{HCl}$ solution and B quantities a value of $-69 \mathrm{mV} / \mathrm{min}$. Several investigations on different metals, e.g., Nickel [36], steel [37], Zinc [38], Zinc alloy [39] and Iron [40] revealed similar behavior which was attributed to an increased rate of dissolution of these metals with increasing the acid concentration. In the present investigation, the steady corrosion potential of the $\mathrm{Cu}$ electrode endings to fixed values after a period extending from $\sim 60$ - $90 \mathrm{~min}$. In these circumstances, it is concluded that the predominant reaction is the anodic dissolution of copper.

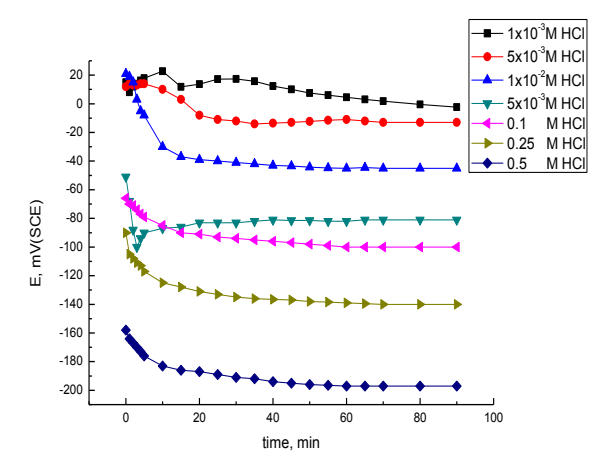

Figure 3. Variation of the open-circuit potential, E, of copper electrode with time, in naturally aerated $\mathrm{HCl}$ acid solutions of varying concentrations.

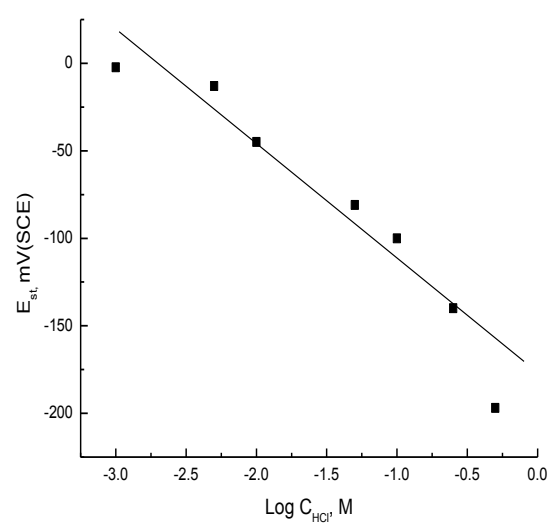

Figure 4. Dependence of the steady-state potential, $E_{\text {st. }}$, of the copper electrode on the logarithm of concentration of naturally aerated $\mathrm{HCl}$ solutions. 


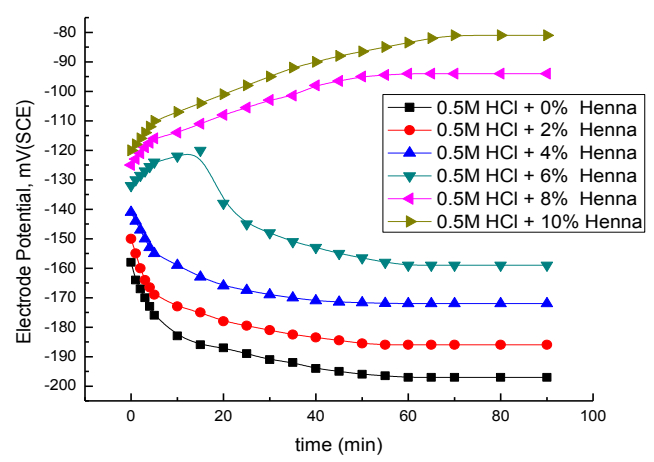

Figure 5. Dependence of the open-circuit potential, E, of the copper electrode on time, in naturally aerated $0.5 \mathrm{M}$ HCl solutions, devoid of- and containing increasing concentrations of henna extract.

The influence of adding increasing percentages of the henna extract on the open circuit potential of the copper electrode immersed in $0.5 \mathrm{M} \mathrm{HCl}$ can be illustrated in Figure 5. The curves of Figure 5 reveal that, the addition of lower concentrations ( $2 \%$ to $4 \%$ ) of henna extract shifts the steady-state potentials toward less active values keeping the shape of the potential-time curves always similar to those reported in the henna extract free solution. This behavior indicates that the dissolution of copper in $\mathrm{HCl}$ seemed to be slightly decreased as a result of the presence of henna extract. When the concentration of henna extract becomes $6 \%$, the potential, E, states to move toward slightly more noble values for a period of $\approx 20$ minutes, before it shifts again in the negative direction to reach a value of $-155 \mathrm{mV}$. In the presence of this concentration of henna extract, this behavior could be attributed to a competitive process involving metal dissolution and metal passivation. However, at higher concentrations of henna extract (8\%-10\%), the electrode potential, E, shifts in the noble direction to reach steady state value which becomes nobler the higher the concentration of the extract. This could be attributed to passivation of copper and the passivation process is the predominant step.

\subsection{Galvanostatic polarization measurements}

Figure 6 shows the anodic and cathodic E-log i polarization curves of copper electrode in naturally aerated solutions of $\mathrm{HCl}$ of increasing concentrations at $25^{\circ} \mathrm{C}$. The results display that with increasing $\mathrm{HCl}$ concentration the anodic polarization curves shift to more negative potentials while the cathodic polarization curves shift to more positive potentials.
The computed values of the anodic and cathodic Tafel slopes, $\beta_{\mathrm{a}}$ and $\beta_{\mathrm{c}}$, as well as, the corrosion potential, $\mathrm{E}_{\text {corr }}$, corrosion current, $\mathrm{i}_{\text {corr, }}$ and polarization resistance, $R_{p}$, are shown in Table 2 . The corrosion current, $\mathrm{i}_{\text {corr }}$, was obtained from the extrapolation of the Tafel lines to the equilibrium potential. The Stern-Geary relationship was for determining the polarization resistance, $R_{p}$ [39]: $\mathrm{i}_{\text {corr }}=\left(\beta_{\mathrm{a}} \beta_{\mathrm{c}} / 2.303\left(\beta_{\mathrm{a}}+\beta_{\mathrm{c}}\right) \mathrm{R}_{\mathrm{p}}\right)=\mathrm{B} / \mathrm{R}_{\mathrm{p}}$

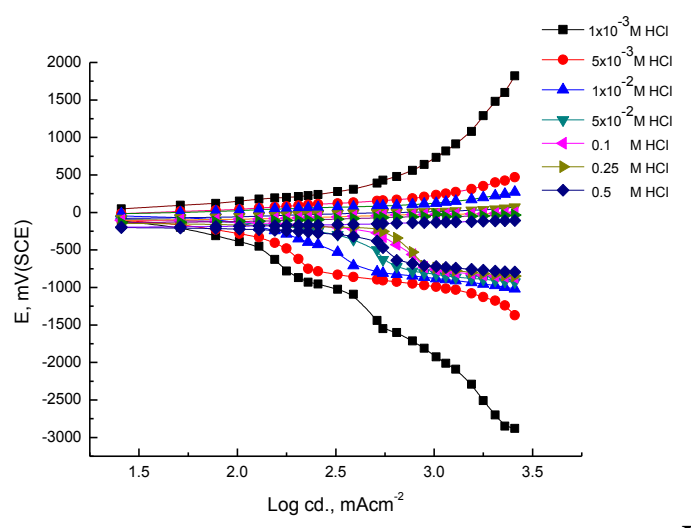

gure 6. Galvanostatic polarization curves of the copper electrode in different concentrations of $\mathrm{HCl}$ solutions at $25^{\circ} \mathrm{C}$.

A review of the curves of Figure 6 and the computed data in Table 2, exposes that both the values of Tafel slopes, $\beta_{\mathrm{a}}$ and $\beta_{\mathrm{c}}$ are affected by expanding the $\mathrm{HCl}$ concentration. At the same time, the values of corrosion current density, $i_{\text {corr }}$, increase decidedly and the values of $R_{p}$ decrease while the corrosion potential is shifted to the more negative potential.

This behavior could be clarified on the basis of the increasing the dissolution of the copper as the concentration of $\mathrm{HCl}$ increased. The same behavior was obtained previously using weight loss and open circuit potential measurements.

Table 2. Kinetic parameters, $\mathbf{E}_{\text {corr., }} \mathbf{I}_{\text {corr., }} \boldsymbol{\beta}_{\mathrm{c}}, \boldsymbol{\beta}_{\mathrm{a}}$ and $\mathbf{R}_{\mathbf{p}}$ for copper electrode at different concentrations of $\mathrm{HCl}$ solution as calculated from Fig. 6.

\begin{tabular}{|c|c|c|c|c|c|}
\hline $\begin{array}{c}\text { Concentration } \\
\text { (HCl), M }\end{array}$ & $\begin{array}{c}-\mathbf{E}_{\text {corr. }}, \\
\mathbf{m V} \\
\text { (SCE) }\end{array}$ & $\begin{array}{l}I_{\text {corr. }}, \\
\mathbf{m A} \\
\mathbf{c m}^{-2}\end{array}$ & $\begin{array}{c}\boldsymbol{\beta}_{\mathrm{c}}, \\
\mathbf{m V} \\
\text { decad }^{-1} \\
\mathrm{e}^{-1}\end{array}$ & $\begin{array}{c}\beta_{a} \\
\mathbf{m V} \\
\text { deca } \\
\mathrm{e}^{-1}\end{array}$ & $\begin{array}{l}\mathbf{R}_{\mathrm{p}}, \\
\mathrm{K} \Omega\end{array}$ \\
\hline 0.001 & 2 & 1.55 & -512 & 235 & 0.045 \\
\hline 0.005 & 13 & 1.58 & -426 & 143 & 0.029 \\
\hline 0.01 & 45 & 1.63 & -300 & 93 & 0.018 \\
\hline 0.05 & 81 & 1.71 & -139 & 72 & 0.012 \\
\hline 0.1 & 100 & 1.82 & -101 & 55 & 0.008 \\
\hline 0.25 & 140 & 1.93 & -89 & 52 & 0.007 \\
\hline 0.5 & 197 & 1.98 & -82 & 42 & 0.006 \\
\hline
\end{tabular}


The influence of adding increasing concentrations of henna extract on the galvanostatic polarization bends of copper electrode dipped in naturally aerated $0.5 \mathrm{M} \mathrm{HCl}$ solution, at room temperature, is appeared in Figure 7. A review of Figure 7 exposes that, at low current densities, both the cathodic and anodic polarization curves are slightly affected giving rise to the pre-Tafel sections. As the applied cathodic and/ or anodic current are extra increased, one of the prevailing cathodic and anodic reactions becomes predominate giving rise to the Tafel region. The corrosion potential is always shifted toward the less active values as the added concentrations of the henna extract is increased while the corrosion current density decreases [40].

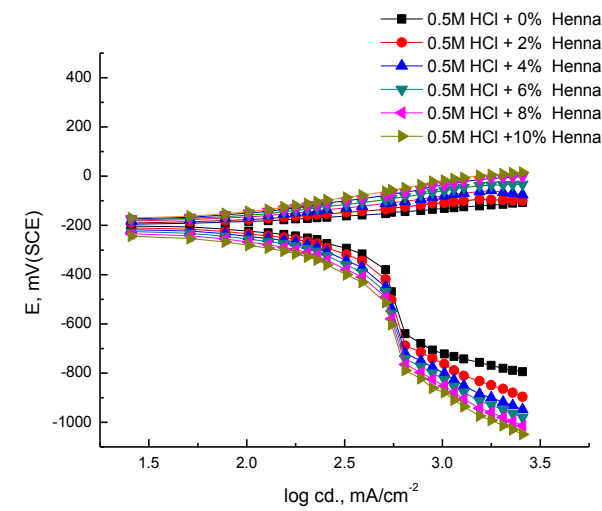

Figure 7. Galvanostatic polarization curves of the copper electrode in $0.5 \mathrm{M} \mathrm{HCl}$ solution free of- and containing increasing percentages of henna extract at $2^{\circ} \mathrm{C}$.

From the curves of Figure 7 and the computed data shown in a Table (3), the values of both $R_{p}$ and IE are increased with increasing the concentration of henna extract.

Table 3. Kinetic parameters, Ecorr., $I_{c o r r .,} \beta_{c}, \beta_{a}, R_{p}$ and IE for the copper electrode in $0.5 \mathrm{M} \mathrm{HCl}$ solution at different percentages of henna extract (HE) as calculated from Figure 7.

\begin{tabular}{|c|c|c|c|c|c|c|}
\hline 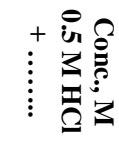 & 离 & 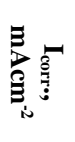 & $\sum_{3}^{2}$ & 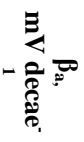 & 页 & $\frac{\partial 9}{x}$ \\
\hline $0 \% \mathrm{HE}$ & 197 & 1.98 & -82 & 42 & 0.0060 & - \\
\hline $2 \% \mathrm{HE}$ & 186 & 1.83 & -98 & 45 & 0.0073 & 7.5 \\
\hline $4 \% \mathrm{HE}$ & 172 & 1.72 & -106 & 53 & 0.0090 & 13.1 \\
\hline $6 \% \mathrm{HE}$ & 159 & 1.41 & -114 & 58 & 0.0118 & 28.7 \\
\hline $8 \% \mathrm{HE}$ & 94 & 1.23 & -121 & 65 & 0.0149 & 37.8 \\
\hline $10 \% \mathrm{HE}$ & 81 & 0.91 & -127 & 77 & 0.0229 & 54.0 \\
\hline
\end{tabular}

Egypt. J. Chem. 65, No. 2 (2022)
The degree of surface coverage, $\theta$, can be calculated from the following equation;

$\theta_{\mathrm{t}}=1-\frac{i_{t}}{i_{o}}$

where $\theta$ is the degree of surface coverage of the metal by the inhibitive henna extract, $i_{t}$ is the current density supported by the copper electrode in the presence of the inhibiting henna extract and $i_{o}$ is current density supported by the electrode in the inhibitor-free solution.

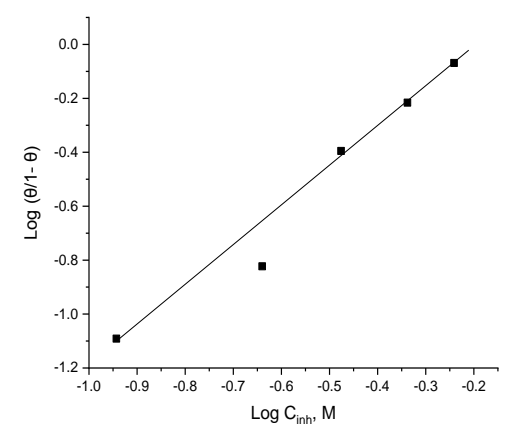

Figure 8. A plot of $\theta$ / (1- $\theta)$ against the concentration of inhibitor, $C_{\text {inh., on a double logarithmic scale. }}$

To correlate $\theta$ to the concentration of the inhibiting henna extract, a plot of $(\theta / 1-\theta)$ versus concentration, $\mathrm{C}_{\mathrm{inh}}$, on a double logarithmic scale, Figure 8 gives rise to a straight line with a slope of about unity which obeys the Langmuir adsorption isotherm [41].

$\log \theta /(1-\theta)=\log \mathrm{K}_{\mathrm{ads} .}+\log \mathrm{C}_{\mathrm{inh}}$ where $\mathrm{K}_{\mathrm{ads}}$ is the equilibrium adsorption constant of the inhibitor. The free energy of inhibition, $\Delta \mathrm{G}^{\circ}{ }_{\text {rep }}$, is derived from the relation:

$\Delta \mathrm{G}_{\text {rep }}^{\circ}=-2.303 \mathrm{RT} \log \left(55.5 \mathrm{~K}_{\mathrm{ads}}\right)$

where 55.5 is the water concentration, $\mathrm{mL} / \mathrm{L}$. The value of $\mathrm{K}_{\mathrm{ads}}$ was calculated from Figure 8 and found to be 1.92. Substitution by the value of $\mathrm{K}_{\mathrm{ads}}$ in equation (12), the value of $\Delta \mathrm{G}^{\circ}$ rep at $25^{\circ} \mathrm{C}$ was calculated and found to be $-11.56 \mathrm{KJmol}^{-1}$. The presence of $\Delta \mathrm{G}^{\circ}$ rep with a moderate negative value indicates that henna extract acts as pitting corrosion inhibitor of copper in $\mathrm{HCl}$ solutions by physical adsorption in competition with $\mathrm{Cl}^{-}$ions for the active sites on the metal surface [42].

Mechanism of Inhibition:

Aqueous extract of the leaves of henna was reported previously to have a good inhibition effect in the case of carbon steel, $\mathrm{Ni}$ and $\mathrm{Zn}$ in alkaline, neutral 
and acidic solutions, using the polarization measurements [43]. In contrast, however, henna extract exhibits no corrosion inhibition action for $\mathrm{Al}$ in $\mathrm{HCl}$ solutions. The failure of henna extracts to inhibit the corrosion of aluminum is attributed to the presence of a protected $\mathrm{Al}_{2} \mathrm{O}_{3}$ passive oxide film on the surface of aluminum, which retards the adsorption of the active species in the henna extracts on the metal surface [44].<smiles>O=C1C=C(O)C(=O)c2ccccc21</smiles>

Lawsone<smiles>O=C1C=C2O[14CH]C[14CH]2O1</smiles>

Lawsone- $\mathrm{Cu}^{+2}$ complex
Figure 9(a)

Figure 9(b)

The active species of Henna extract is Lawsone as shown in Figure 9(a). It has a phenolic group, benzene ring, and p-benzoquinone unit. In our present investigation, it is assumed that the inhibition action of henna extract is due the formation of coordinate links between the soluble $\mathrm{Cu}^{2+}$ and both the oxygen of phenolic aromatic ring and $\mathrm{C}=0$ group of the $\mathrm{p}$-benzoquinone, giving rise to the formation of $\mathrm{Cu}^{2+}$ - Lawsone complex. The latter is easily precipitated on the active anodic sites of copper surface, Figure 9(b), causing inhibition of corrosion. On the other hand, the simultaneous formation of cupric hydroxide, $\mathrm{Cu}(\mathrm{OH})_{2}$, on the cathodic sites of the metal surface cannot be excluded. This hydroxide could repair some of the cathodic sites on the metal surface $[45,46]$.

\section{Conclusions}

Henna extract is used in the present investigation to inhibit the dissolution of copper in $\mathrm{HCl}$ solution. The active compound of the henna compound is Lawsone. From the open circuit potential measurements, weight loss measurements, and galvanostatic polarization techniques, the subsequent conclusions can be drawn:

- The henna extract has good inhibition efficiency in controlling the corrosion of copper in a $0.5 \mathrm{M} \mathrm{HCl}$ solution.

- The IE of Lawsone increases with increasing concentrations.

- It has high IE in the ranged 6-10\% of the extract at $25^{\circ} \mathrm{C}$.
- The protecting layer consists of $\mathrm{Cu}^{2+}$ - Lawsone complex and $\mathrm{Cu}(\mathrm{OH})_{2}$.

- The results obtained for all techniques used are in good agreement.

\section{Conflicts of interest}

"There are no conflicts to declare".

\section{Formatting of funding sources}

"There are no funding sources".

\section{ACKNOWLEDGEMENT}

Thanks and appreciation to Zagazig University for assistance and facilities provided.

\section{References}

1 Feng Y., Siow K. S., Teo W. K., Tan K. L. and

Hsieh A. K., Corrosion Mechanisms and

Products of Copper in Aqueous Solutions at

Various pH Values, NACE., 53(5), 389 (1997).

2 Sherif E. M. and Park S. M., Inhibition of Copper

Corrosion in Acidic Pickling Solutions by $N$ -

phenyl-1,4-Phenylenediamine, Electrochim.

Acta, 51, 4665 (2006).

3 El-Sayed Sherif M., Erasmus R. S. and Comins J.

D., Inhibition of copper corrosion in acidic

chloride pickling solutions by 5-(3-

aminophenyl)-tetrazole as a corrosion inhibitor,

J. Colloid \& Inter. Sci., 306, 96 (2007).

4 El-Sayed Sherif M., Erasmus R. S. and Comins J.

D., Inhibition of copper corrosion in acidic

chloride pickling solutions by 5-(3-

aminophenyl)-tetrazole as a corrosion inhibitor, Corros. Sci., 50, 3439 (2008).

5 El-Sayed Sherif M., Corrosion mitigation of copper in acidic chloride pickling solutions by 2 -amino5-ethyl-1,3,4-thiadiazole, J. Mater. Eng.

Perform. 19, 873 (2010).

6 El-Sayed Sherif M., Electrochemical and Gravimetric Corrosion Inhibition Investigations of a Heterocyclic Schiff Base Derived from 3Formylindole, Int. J. Electrochem. Sci., 7, 1482(2012).

7 Maqsood Ahmad Malik, Mahdi Ali Hashim, Firdosa Nabi, Shaeel Ahmed AL-Thabaiti and Zaheer Khan, Anti-corrosion Ability of Surfactants: A Review, Int. J. Electrochem. Sci., 6, 1927, (2011). 
8 El-Sayed Sherif M. and Almajid A. A., Surface protection of copper in aerated $3.5 \%$ sodium chloride solutions by 3-amino-5-mercapto1,2,4-triazole as a copper corrosion inhibitor, $J$. Appl. Electrochem., 40, 1555 (2010).

9 El Warraky A., El Shayeb H. A. and Sherif E. M., pitting corrosion of copper in chloride solutions, Anti-Corros. Methods Mater, 51, 52 (2004).

10 Antonijevic M. M., Alagic S. C., Petrovic M. B., Radovanovic M. B. and Stamenkovic A. T., The Influence of $\mathrm{pH}$ on Electrochemical Behavior of Copper in Presence of Chloride Ions, Int. J. Electrochem. Sci., 4, 516 (2009).

11 Zhang D-Q., Gao L-X. and Zhou G-D., Inhibition of copper by bis-(1-benzotriazolemethylene) (2,5-thiadiazoly)-disulfide in chloride media, J. Appl. Surf. Sci., 225, 287 (2004).

12 Antonijevic M. M. and Petrovic M. M., Copper Corrosion Inhibitors. A review, Int. J. Electrochem. Sci., 3, 1 (2008).

13 Foad E.E., El-Sherbini Mostafa Khalil M. H., Eman H. Ismail, Soha S. Tobar16th International Conference on AEROSPACE SCIENCES \& AVIATION TECHNOLOGY, ASAT, 16, May 26 - 28 (2015),

14 Baeza H., Guzman M., Ortega P. and Vera L., corrosion inhibition of copper in $0.5 \mathrm{M}$ hydrochloric acid by1,3,4-thiadiazole-2,5-dithiol, J, Chil. Chem. Soc., 48, 3 (2003).

15 El-Sayed Sherif M., Corrosion Behavior of Copper in $0.5 \mathrm{M}$ Hydrochloric Acid Pickling Solutions and its Inhibition by 3-Amino-1,2,4triazole and 3-Amino-5-mercapto-1,2,4-triazole, Int. J. Electrochem. Sci., 7, 1884-1897 (2012).

16 Satpati A. K. and Reddy A. V. R., Electrochemical Study on Corrosion Inhibition of Copper in Hydrochloric Acid Medium and the Rotating Ring-Disc Voltammetry for Studying the Dissolution, Arabian Journal of Chemistry, 13(1),481-544 (2020).

17 Zohdy K. M., El-Sherif R. M., Ramkumar S. and El-Shamy A. M., Quantum and electrochemical studies of the hydrogen evolution findings in corrosion reactions of mild steel in acidic medium, Upstream Oil and Gas Technology 6 , 100025(2021).

18 Houyi Ma, Shenhao Chen. Z, Shiyong Zhao, Xiangqian Liu and Degang Lib, A Study of Corrosion Behavior of Copper in Acidic
Solutions Containing Cetyltrimethylammonium Bromide, Journal of The Electrochemical Society, 148(11), 482-488 (2001).

19 Fadel Wedian1 A., Mahmoud, Al-Qudah1 and M. Ghassab Al-Mazaideh, Corrosion behavior of copper in acid solutions, Int. J. Electrochem. Sci., 12, 4664 (2017).

20 Wan Nik W. B., Zulkifli F., Sulaiman O., Samo K. B. and Rosliza R., Study of Henna (Lawsonia inermis) as natural corrosion inhibitor for aluminum alloy in seawater, IOP Conference Series: Materials Science and Engineering (2012).

21 Okorosaye K., Hart Kalada G., Orubite-James and Abosede O., International Journal of Advanced Research in Chemical Science (IJARCS) 3(12), 34-40 (2016).

22 Ostovari A., Hoseinieh S. M., Peikari M., Shadizadeh S. R. and S. Hashemi, Corrosion inhibition of mild steel in $1 \mathrm{M} \mathrm{HCl}$ solution by henna extract: A comparative study of the inhibition by henna and its constituents (Lawsone, Gallic acid, $\alpha$-D-Glucose and Tannic acid), J. Corrosion Science, 51, 1935 (2009).

23 Shyamala Devi B., Rajam K. and Teyasndari J., Corrosion inhibition by an aqueous extract of Henna leaves (Lawsonia Inermis L), ZASTITA MATERIJALA, 50, 77 (2009).

24 Raja P. B. and Sethuraman M. G., Natural products as corrosion inhibitor for metals in corrosive media, a review, Materials Letters, 62, 113 (2008).

25 Chetouani A. and Hammouti B., Corrosion inhibition of iron in hydrochloric acid solutions by naturally henna, Bulletin of Electrochemistry, 19, 23 (2003).

26 Muhammad Bashir Ibrahim, Zakariyau Sulaiman, Bishir Usman, Muhammad Adamu Ibrahim, Effect of Henna Leaves on the Corrosion Inhibition of Tin in Acidic and Alkaline Media, World Journal of Applied Chemistry, 4(4), 45 (2019).

27 Zohdy K. M., El-Sherif R. M. and El-Shamy A. M., Corrosion and Passivation Behaviors of Tin in Aqueous Solutions of Different $\mathrm{pH}$, Journal of Bio-and Tribo-Corrosion 7 (2), 1-7(2021).

28 Fouda A. S., Hegazi M. M, Ali. and El-Azaly, Henna Extract as Green Corrosion Inhibitor for 
Carbon Steel in Hydrochloric Acid Solution, Int. J. Electrochem. Sci., 14, 4668-4682 (2019).

29 Hajar H.M., Zulkifli F., Mohd Sabri M.G., Fitriadhy A. and Wan Nik W.B., Lawsonia Inermis Performance as Corrosion Inhibitor for Mild Steel in Seawater, International Journal of Chem Tech Research CODEN (USA): 9(8) 600608(2016).

30 Zulkifli F., Nora'aini Ali Sukeri M. Yusof M., Isa M.I.N., Yabuki A. and Wan Nik W.B., Henna leaves extract as a corrosion inhibitor in acrylic resin coating, Progress in Organic Coatings, 105, 310-319 April (2017).

31Zahra Khoshkhou, Maryam Torkghashghaei, Amin Rabiei Baboukani, Corrosion Inhibition of Henna Extract on Carbon Steel with Hybrid Coating TMSM-PMMA in $\mathrm{HCl}$ Solution, Open Journal of Synthesis Theory and Applications, 7(1) 1(2018).

32 El-Shamy M., El-Hadek M. A., Nassef A. E. and El-Bindary R. A., Box-Behnken design to enhance the corrosion resistance of high strength steel alloy in 3.5 wt.\% NaCl solution, Moroccan Journal of Chemistry 8 (4), 8-4, 788-800 (2020).

33 El-Bindary R., El-Shamy A. M., Elhadek M. A. and Nassef A., Statistical Analysis of the Inhibition of Carbon Steel Corrosion in 3.5 wt.\% $\mathrm{NaCl}$ Solution Using Lawsonia Extract, PortSaid Engineering Research Journal, 25 (1), 101113(2021).

34 Abd El Kader J. M. and Shams El Din A. M., Critical pitting temperature for Type 254 SMO stainless steel in chloride solutions, Br. Corros. J., 14, 40 (1979).

35 Abd El Haleem S. M., Abd El Aal E. E., El Wanees S. Abd and Diab A., Variation in the pitting corrosion current in relation to the concentration of the aggressive and the inhibitive anions, Corros. Sci., 52, 3875 (2010).

36 Abd El Aal E. E., Oxide film formation on zinc in borate solutions under open circuit, Corros. Sci., 50, 41 (2008).

37 Abd El Haleem S. M. and Abd El-Rehim S. S., Corrosion behavior of commercial $\mathrm{Zn}$-Ti alloy in aqueous salt solutions, Revue-Rommanie $\mathrm{Di}$ Chimie, 25, 493(1980).

38 Abd El Aal E. E. and Abd El Haleem S. M., Kinetics of oxide film growth and destruction on iron surface in carbonate solutions, Corros. Engine. Science and Techn. 43, 219(2008).

39 Stern M. and Geary A. L., Electrochemical Polarization, I. A Theoretical Analysis of the Shape of Polarization Curves, J. Electrochem. Soc., 104, 56 (1957).

40 El-Etre A. Y. and El-Tantawy Z., Inhibition of metallic corrosion using Ficus extract, Portugaliae Electrochimica Acta, 24, 347 (2006).

41 Ahamad I. and Quraishi MA, Bis (benzimidazol2-yl) disulphide: an efficient water-soluble inhibitor for corrosion of mild steel in acid media, Corrosion Science, 51(9), 20062013(2009).

42 Ormellese M., Bolzoni F., Lazzari L., and Pedeferri P., Effect of corrosion inhibitors on the initiation of chloride- induced corrosion on reinforced concrete structures, Material and Corrosion, 59, 98-106 (2008).

43 El-Etre A. Y., Abdallah M. and El-Tantawy Z. E., Corrosion inhibition of some metals using lawsonia extract, Corrosion Science, 2 (47), 385 (2005).

44 Wan Nik W. B., Zulkifli F., Sulaiman O., Samo K. B. and Rosliza R., Study of Henna (Lawsonia inermis) as Natural Corrosion Inhibitor for Aluminum Alloy in Seawater, Materials Science and Engineering, 36, 1-7 (2012).

45 Sekine I. and Hirakawa Y., Effect of 1Hydroxyethylidene-1, 1-Diphosphonic Acid on the Corrosion of SS 41 Steel in $0.3 \%$ Sodium Chloride Solution, Corrosion, 42, 272 (1986).

46 Rajendran S., Sridevi S. P., Anthony N., John A. and M. Amalraj, Corrosion behavior of carbon steel in polyvinyl alcohol, Anti-Corrosion Methods and Materials, 52, 102 (2005). 